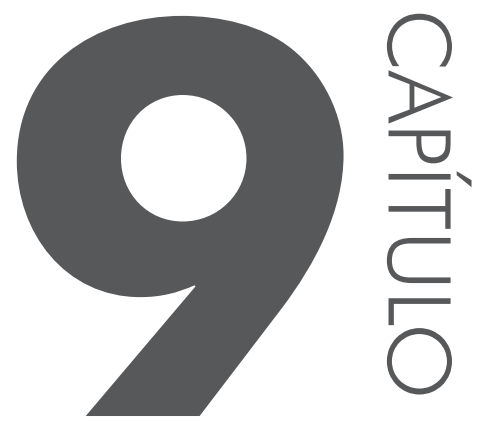

\title{
ACEITABILIDADE DE EXTRATO DE SOJA ELABORADO COM GRÃOS DE GENÓTIPOS BRASILEIROS CONVENCIONAIS E TRANSGÊNICOS
}

Rafael Luiz Pirolli Vilas Boas Vera de Toledo Benassi José Marcos Gontijo Mandarino Juliany Piazzon Gomes

\section{INTRODUÇÃO}

A soja é o principal grão oleaginoso cultivado no mundo e a cultura líder do agronegócio brasileiro. O Brasil é o segundo produtor em contexto mundial (DALL'AGNOL et al., 2007), possuindo qualidade premium no óleo comestível 
e no farelo proteico, o que permite sua entrada em mercados exigentes, como União Europeia e Japão (BRASIL, 2013).

A soja possui um alto valor nutricional, apresentando em sua composição elevado teor de proteínas e lipídios (ROSSI; ROSSI, 2010). Uma das principais funções das proteínas no organismo humano é a síntese de novos tecidos; já o óleo presente nos grãos fornece as calorias necessárias para que as proteínas possam realizar sua função (CARRÃO-PANIZZI; MANDARINO, 1998).

Todavia, os grãos de soja in natura contêm alguns componentes indesejáveis, como as lipoxigenases, que podem reduzir sua aceitabilidade sensorial (BORDINGNON; MANDARINO, 1994). A enzima lipoxigenase, que promove a oxidação dos ácidos graxos poli-insaturados, com consequente formação de aldeídos (n-pentanal e n-hexanal), é responsável por um sabor desagradável (ROSSI; ROSSI, 2010), conhecido como beany flavor, sabor de ranço ou "feijão cru" (EMPRESA BRASILEIRA DE PESQUISA AGROPECUÁRIA, 2013). A reação ocorre quando o grão moído ou quebrado entra em contato com água fria, proporcionando o encontro entre a lipoxigenase e ácidos graxos. O sabor resultante, que é bem aceito pelos orientais, pode parecer exótico ao paladar dos brasileiros, afastando a soja de seus hábitos alimentares. A enzima lipoxigenase pode ser inativada pelo calor. Portanto, o uso de água fervente por cinco minutos antes dos processamentos é suficiente para inativar as enzimas (BENASSI; MANDARINO; CARRÃO-PANIZZI, 2012).

O extrato de soja apresenta características semelhantes ao leite de vaca, principalmente em sua aparência e composição (ROSSI; ROSSI, 2010). Por ser de origem vegetal e não possuir colesterol, o extrato de soja pode atender a necessidades de pessoas que buscam hábitos alimentares saudáveis, sendo também uma alternativa para pessoas alérgicas à proteína do leite ou intolerantes ao seu açúcar (lactose) (CARRÃO-PANNIZI; MANDARINO, 1998).

Para obter boa aceitação, o extrato de soja deve ser produzido sem o desenvolvimento de beany flavor. Por isso, as indústrias de alimentos têm investido em tecnologia para obtenção de bebidas à base de soja de alta qualidade, com ampla variedade de produtos (sabores variados, em versões light e normal), enriquecidas com nutrientes e fibras, em embalagens práticas e modernas, de modo a aumentar sua inclusão na dieta da população ocidental (ROSSI; ROSSI, 2010). As cultivares de soja podem também influenciar no rendimento e na qualidade sensorial do extrato produzido.

Assim, o objetivo do presente trabalho foi verificar a aceitação sensorial do extrato de soja de diferentes genótipos brasileiros convencionais e transgênicos.

\section{SOJA}

A soja cultivada pelos chineses ancestrais era uma planta rasteira, que evoluiu devido a cruzamentos naturais de duas espécies selvagens melhoradas por 
cientistas da antiga China (EMBRAPA, 2013). A soja possui alto valor nutricional e sua importância na alimentação foi percebida pelos chineses há mais de 4000 anos. Nos Estados Unidos (EUA), a importância comercial foi descoberta após 1920 (ROSSI; ROSSI, 2010).

A introdução da soja no Brasil e o seu desenvolvimento iniciaram-se com testes no estado da Bahia em 1882, porém o germoplasma trazido dos Estados Unidos não se adaptou devido às condições de baixa latitude. Em 1900, foi adaptada no Rio Grande do Sul, onde as condições climáticas são semelhantes às da região sul dos EUA. A cultura da soja permaneceu ignorada no Brasil entre os anos de 1882 a 1950, quando a produção era destinada à forragem e alimentação de suínos. Na década de 1960, começou sua trajetória de crescimento e, em menos de vinte anos, converteu-se na cultura líder do agronegócio brasileiro (DALL'AGNOL et al., 2007).

A soja é o principal grão oleaginoso cultivado no mundo. Em comparação com outras grandes culturas de grãos, a soja foi a que mais cresceu nos últimos 37 anos, tanto no Brasil quanto em escala mundial. O Brasil é o segundo produtor em contexto mundial, podendo se tornar o primeiro devido a limitações de expansão de áreas produtoras de outros países e por possuir domínio tecnológico para produzir em regiões tropicais com baixa latitude (DALL'AGNOL et al., 2007).

O décimo levantamento da safra de soja de julho de 2013 mostra que nessa temporada a soja atingiu o recorde de 27.721,5 mil hectares, apresentando um incremento de $10,7 \%$ em comparação com o verificado na temporada 2011/12 25.042,2 mil hectares, superando o recorde nacional de 2012, onde a produtividade média atingiu $2.651 \mathrm{~kg} / \mathrm{ha}$. Esse fato pode ser explicado pela ocorrência de clima adequado em importantes fases do desenvolvimento da lavoura, principalmente na região sul (COMPANHIA NACIONAL DE ABASTECIMENTO, 2013).

A indústria nacional transforma, por ano, 30,7 milhões de toneladas de soja em 5,8 milhões de toneladas de óleo comestível e 23,5 milhões de toneladas de farelo proteico, que possuem alto teor de proteínas e padrão de qualidade premium, permitindo sua entrada em mercados exigentes como União Europeia e Japão (BRASIL, 2013).

A soja é uma leguminosa rica em termos nutricionais, apresentando elevado teor de proteínas e lipídios: possui, em média, 40\% de proteínas, 20\% de lipídios, $30 \%$ de carboidratos, $5 \%$ de cinzas e $5 \%$ de fibras. Com seu considerável valor nutricional, a soja era utilizada como importante componente na alimentação dos chineses há mais de quatro mil anos. Além disso, hoje se sabe que a soja apresenta vários componentes bioativos, que a caracterizam como um alimento funcional (ROSSI; ROSSI, 2010).

Uma alimentação adequada é necessária para o organismo adquirir resistência contra doenças, aumentar a vida média e auxiliar o desenvolvimento mental. Os 
alimentos de origem animal são as fontes proteicas mais tradicionalmente consumidas; no Brasil, segundo produtor mundial, os derivados da soja deveriam estar ao alcance da população, como uma alternativa proteica viável, capaz, inclusive, de solucionar problemas de desnutrição. O óleo presente nos grãos de soja fornece as calorias necessárias ao organismo para metabolizar as proteínas ingeridas para a síntese de novos tecidos (CARRÃO-PANNIZI; MANDARINO, 1998).

A falta de hábito e a necessidade de praticidade no preparo dos pratos pode ter mantido a soja afastada da dieta do brasileiro (FELBERG et al., 2005), porém, isso tem se alterado gradativamente, devido à introdução no mercado de grande número de produtos derivados de soja. Alguns dos mais conhecidos são o óleo de cozinha, a proteína texturizada, o isolado proteico, o extrato, o tofu e os produtos tipo iogurte (ROSSI; ROSSI, 2010).

Os processos tecnológicos para obtenção de produtos à base de soja visam reduzir características indesejáveis de sabor (FELBERG, et al., 2005). A soja in natura possui componentes indesejáveis como as lipoxigenases, que reduzem a sua aceitabilidade (BORDINGNON; MANDARINO, 1994).

As lipoxigenases são enzimas que catalisam a peroxidação de ácidos graxos poli-insaturados e seus ésteres, produzindo compostos voláteis, tais como cetonas, aldeídos e álcoois. Esses compostos são responsáveis pelo sabor de ranço ou "feijão cru" principalmente quando a soja é colocada de molho em água fria (EMPRESA BRASILEIRA DE PESQUISA AGROPECUÁRIA, 2013). Também ao realizar a moagem, a enzima lipoxigenase e o substrato são liberados e, se houver água em quantidade suficiente, a enzima catalisa a oxidação do substrato, produzindo os compostos indesejáveis. A temperatura da mistura entre água e soja influencia na formação de voláteis durante a moagem. A temperatura da mistura deve ser alta: quando a soja é moída a $80{ }^{\circ} \mathrm{C}$ ou mais, a formação de voláteis é praticamente inexistente (ROSSI; ROSSI, 2010).

Alguns fatores antinutricionais estão presentes nos grãos de soja in natura, que são: inibidores de tripsina, ácido fítico, hemaglutinas e fator bociogênico. Os inibidores de tripsina têm a maior atenção dos profissionais da área da saúde, porque podem promover uma hipertrofia pancreática. Em contrapartida, pequenas concentrações dos inibidores de tripsina nos alimentos derivados de soja podem atuar na redução do risco de determinados tipos de cânceres e na redução do nível sérico do colesterol. Com a ação do calor, os inibidores de tripsina perdem a sua atividade ao se ligarem a outros componentes do grão (ROSSI; ROSSI, 2010).

\subsection{Extrato de soja}

O extrato de soja foi processado pela primeira vez na China, no século II a.C. Suas características são semelhantes às do leite de vaca, principalmente na 
aparência e composição. O extrato apresenta, em média, a cada $100 \mathrm{ml}: 2,5 \mathrm{~g}$ de carboidratos; 3,4 g de proteínas; 2,3 g de lipídeos; 40 mg de cálcio; $105 \mathrm{mg}$ de potássio; 1,2 mg de ferro; 40 ug de vitamina B1 e 120 ug de vitamina B2 (ROSSI; ROSSI, 2010).

Harry Willis Miller, médico americano missionário na China, melhorou a qualidade do extrato de soja por inovações no processo, iniciando a produção em massa na China e em vários países. Inovações tecnológicas que reduziram o beany flavor (sabor de feijão cru) tornaram o extrato mais popular no ocidente (ROSSI; ROSSI, 2010).

O extrato de soja pode atender a necessidades de pessoas que buscam hábitos alimentares mais saudáveis, por não possuir colesterol; também é uma alternativa nutritiva a pessoas intolerantes à lactose (açúcar) ou alérgicas à proteína do leite. $\mathrm{O}$ extrato de soja é deficiente em cálcio e vitamina $\mathrm{A}$, por isso, quando utilizado em dietas de lactantes, necessita receber suplementação (CARRÃO-PANIZZI, 1988). Em comparação com o leite de vaca, o extrato de soja contém maiores concentrações de ferro, ácidos graxos insaturados e niacina. Em relação às proteínas, o extrato de soja possui deficiência em aminoácidos sulfurados, que podem ser encontrados nos cereais - e, quando realizada essa combinação, é possível obter um alimento completo em termos proteicos (ROSSI; ROSSI, 2010).

Atualmente, o interesse da população em consumir alimentos saudáveis faz com que a indústria de alimentos realize investimentos no aprimoramento e disponibilização de extrato de soja de alta qualidade no mercado, que apresenta ampla variedade de bebidas à base de soja, em versões light e normal, enriquecidas com nutrientes e fibras, e em embalagens práticas e modernas. Tudo isso tem contribuído para a inclusão desse tipo de bebida na dieta do brasileiro (ROSSI; ROSSI, 2010). Conforme observado por Zadinello et al. (2010), ao adicionar sucos de frutas, aromatizantes, entre outros produtos que mascaram qualquer sabor amargo, ou adstringente, presente na soja, melhora-se a qualidade do extrato e, consequentemente, seu consumo pela população brasileira pode aumentar.

Em 1985, foi lançada no Brasil a primeira bebida à base de soja, o produto Tonyu, da Yakult. Em 1996, a marca AdeS, da Unilever, chegou ao Brasil e foi ganhando destaque; dados de 2010 apontavam essa marca como líder do mercado brasileiro, com 65,9\% de participação em volume (SOARES, 2011).

$\mathrm{O}$ mercado de bebidas à base de soja vem crescendo e aumentando seu espaço na mesa dos brasileiros. No final de 2010 , mais de $40 \%$ da população consumia esse tipo de bebidas, com maior concentração nas classes A e B, porém aumentando na classe C (SOARES, 2011).

Segundo Mendonça (2010), o consumo per capita de bebidas à base de soja no Brasil em 2010 foi de 1,28 litros por ano, enquanto a ABIR (Associação Bra- 
sileira de Indústrias de Refrigerantes e de Bebidas não Alcoólicas), estimou consumo da ordem de 533 milhões de litros em 2011, com um valor per capita de 2,8 litros por ano (DADOS, 2011). Baseado nesses valores, pode-se estimar que houve um aumento expressivo (quase $120 \%$ ) no consumo de bebidas à base de soja nesse curto espaço de tempo.

\subsection{Análise sensorial}

A análise sensorial é uma disciplina científica utilizada para evocar, medir, analisar e interpretar reações às características de alimentos e materiais como são percebidas pelos sentidos da visão, olfato, gosto, tato e audição (MINIM, 2006). Constitui-se num importante instrumento para indústrias de alimentos e instituições de pesquisa, podendo ser utilizada no acompanhamento das etapas de desenvolvimento de produto, avaliação no efeito de alterações/substituições das matérias-primas, redução de custos, seleção de fornecedores, embalagem, controle de qualidade, armazenamento (vida útil do produto), assim como estudos de aceitação e decisão de compra ou não do produto pelos consumidores (DUTCOSKY, 2007).

Por meio da análise sensorial, é possível identificar diferenças entre os alimentos, e definir atributos que dificilmente seriam detectados por outros procedimentos analíticos (STONE; SIDEL, 2004). Os testes sensoriais afetivos medem o quanto um consumidor ou potencial consumidor gosta ou desgosta de um produto, avaliando preferência ou aceitabilidade (DUTCOSKY, 2007).

Existem várias escalas para medir a aceitação; uma das mais usadas é a escala hedônica. É uma escala facilmente compreendida pelos consumidores, sendo possível obter resultados confiáveis. Há diferentes tipos de escalas hedônicas, estruturadas ou não. A não estruturada é uma linha demarcada apenas em seus pontos extremos (por exemplo, no esquerdo, com o termo "desgostei extremamente", e, no direito, "gostei extremamente"), enquanto a escala estruturada apresenta pontos intermediários. Entre as estruturadas, podemos ter escalas apenas numéricas, faciais (utilizadas com crianças ou pessoas que não conseguem ler) ou verbais, as quais exigem uma escolha apropriada das palavras, evitando expressões ambíguas (que possam causar confusão e dificultar a decisão de resposta do consumidor) e permitindo dar uma ideia de ordem sucessiva dos intervalos (MINIM, 2006).

Os dados obtidos por avaliação de escala hedônica são frequentemente avaliados por meio de histogramas, tornando-se possível a visualização da segmentação dos valores hedônicos de cada amostra, revelando o seu nível de aceitação e rejeição e permitindo a comparação dos desempenhos de duas ou mais amostras, ou da análise de variância (Anova) e teste de comparação de médias, de forma a poder tirar alguma conclusão a respeito da opinião dos julgadores sobre um ou mais produtos (MINIM, 2006). 


\section{MATERIAS E MÉTODOS}

Trata-se de uma pesquisa experimental realizada no período de 06/06/2013 a 03/02/2014, com a finalidade de verificar a aceitabilidade do extrato de soja de oito genótipos diferentes, convencionais e transgênicos, por meio de análise sensorial.

\subsection{Material em estudo}

Os genótipos de soja utilizados são provenientes do Programa de Melhoramento Genético da Embrapa Soja - Empresa Brasileira de Pesquisa Agropecuária, do Ministério da Agricultura, Pecuária e Abastecimento. São elas: as cultivares convencionais BRS 232, BRS 284, BRS 361 e BRS 317; e as cultivares transgênicas BRS 359 RR, BRS 360 RR, BRS 378 RR e a linhagem BR 09-55277 RR1. Todas foram cultivadas em Londrina e em Ponta Grossa, na safra 2012/13.

Os reagentes necessários para realização dos métodos oficiais foram fornecidos pela Embrapa Soja, assim como os aparelhos e equipamentos para as análises físico-químicas. Frascos de vidro e garrafas plásticas para armazenamento do extrato foram adquiridos pelo autor do trabalho.

As determinações da composição proximal foram realizadas no laboratório de análises físico-químicas e a obtenção do extrato de soja e a análise sensorial foram realizadas na Cozinha Experimental, ambos na Embrapa Soja, Londrina, PR.

\subsection{Obtenção do extrato de soja}

O extrato de soja foi obtido na cozinha experimental da Embrapa Soja, com auxílio do equipamento Sojamac mod. MJ720.

Foram pesados $170 \mathrm{~g}$ de grãos de soja em balança semianalítica (OHAUS, NO.CT1200) e estes foram adicionados a um recipiente de alumínio com $700 \mathrm{ml}$ de água em ebulição. Aguardou-se até a água entrar novamente em ebulição e prosseguiu-se a fervura por 5 min. Após o tratamento térmico, os grãos foram transferidos para um recipiente tampado e ficaram em repouso durante duas horas para a maceração. Concluído o tempo de maceração, a água foi drenada, e os grãos, lavados em água corrente à temperatura ambiente, para retirada de possíveis impurezas. Depois os grãos foram pesados novamente, e anotou-se o valor para cálculo da água absorvida (diferença entre o peso dos grãos macerados e dos grãos secos).

Do total de grãos hidratados, foram pesados 315 g para o processamento, quantidade adequada ao volume do equipamento. Esses grãos foram colocados no equipamento, adicionando-se também 21 de água em temperatura ambiente para o processamento, o qual ocorre automaticamente ao ligar o equipamento. Durante 25 minutos, ocorreu o aquecimento da água e quatro etapas de tritura- 
ção. Após o processamento, o extrato de soja foi separado do resíduo por filtração em tecido de algodão; tanto o extrato como o resíduo obtido foram pesados para cálculo posterior do rendimento do processo.

Cada batelada de extrato foi colocada em recipiente de alumínio e aquecida em fogão industrial a gás DAKO 02431 até atingir a ebulição, sendo armazenada sob refrigeração. Para cada um dos genótipos, foram realizadas quatro bateladas, obtendo-se aproximadamente 7,5 $1 \mathrm{de}$ extrato. Desse total, foram retirados aproximadamente $800 \mathrm{ml}$, que foram acondicionados em 4 frascos de vidro de $250 \mathrm{ml}$, para liofilização (a fim de obter material para as análises de laboratório), e o restante foi formulado $(0,25 \%$ de $\mathrm{NaCl}$ e $6 \%$ de sacarose), dividido em 6 frascos plásticos tampados de 11 e armazenado sob congelamento, até a realização da análise sensorial.

O procedimento descrito pode ser visualizado na Figura 9.1.

\subsection{Análise sensorial}

As amostras de extrato de soja foram previamente descongeladas e mantidas sob refrigeração até o momento da análise. Os provadores foram recrutados entre a equipe de empregados e estagiários da empresa, e esclarecidos a respeito da análise, preenchendo um termo de consentimento e um questionário contendo dados pessoais e informações sobre o conhecimento dos produtos à base de soja. O delineamento utilizado foi do tipo completo, totalmente aleatorizado e balanceado. A análise sensorial foi realizada em cabines individuais, nas quais o provador recebeu uma amostra por vez, devidamente codificada com números de três dígitos, bem como uma ficha de avaliação, contendo escala hedônica es-

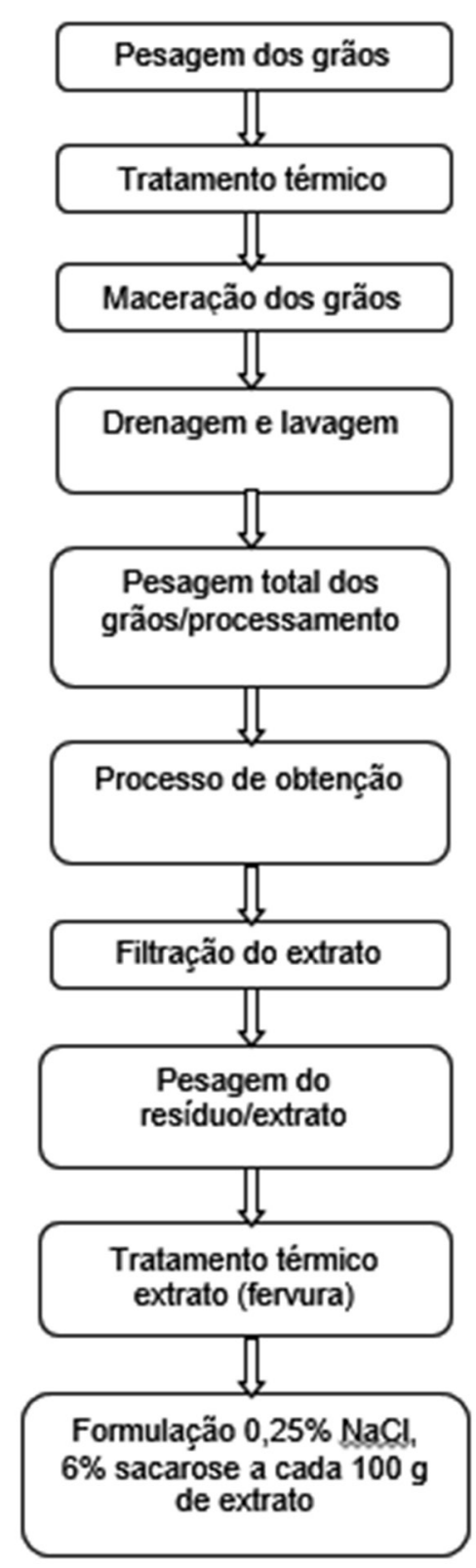

Figura 9.1 Etapas de obtenção do extrato de soja 
truturada de 9 pontos, onde 1 = desgostei muitíssimo e 9 = gostei muitíssimo. Após, foi realizado um teste de preferência de ordenação.

\subsection{Liofilização}

Retirou-se aproximadamente $2 \mathrm{ml}$ do extrato líquido de cada amostra para determinação de umidade em estufa a $105{ }^{\circ} \mathrm{C}$, até peso constante. Em seguida, congelou-se as amostras de extrato de soja para liofilização em liofilizador (Liobras, mod. L-101), com temperatura de $-55^{\circ} \mathrm{C}$ e pressão de $200 \mu \mathrm{m}$ de $\mathrm{Hg}$, até secagem completa $(72 \mathrm{~h})$. Essas amostras liofilizadas foram armazenadas em potes plásticos até o momento das análises para determinação da composição proximal.

A composição proximal do extrato de soja líquido foi calculado utilizando-se os teores de óleo, proteínas, cinzas e carboidratos encontrados na liofilização e transformados em base úmida, em função dos teores de umidade inicial de cada extrato líquido.

\subsection{Análise do processamento}

Durante o processamento dos grãos de soja para obtenção do extrato, foram registrados os pesos dos grãos (secos e macerados) e do extrato produzido com cada cultivar. Para calcular a quantidade de água absorvida (expressa em g) pelos grãos de cada uma das cultivares, foi subtraído o peso dos grãos secos do peso dos grãos macerados. Para calcular o rendimento em extrato, foi dividido o peso do extrato pelo peso de grãos secos (multiplicando por 100, para expressar em g extrato/100 g de grãos). Para cada cultivar, foram realizadas quatro repetições. Os resultados obtidos foram submetidos à análise de variância.

\subsection{Determinação de umidade}

A umidade foi determinada de acordo com as normas analíticas do Instituto Adolfo Lutz (2008): foram pesados aproximadamente $2 \mathrm{~g}$ da amostra em cápsula de metal, previamente tarada; a amostra foi aquecida durante 18 horas em estufa S. E. Fanem MOD 310 a $105^{\circ} \mathrm{C}$, resfriada em dessecador até a temperatura ambiente e então pesada. Essa operação foi repetida até o peso constante.

\subsection{Determinação do teor de óleo}

O teor de lipídeos (óleo) foi determinado de acordo com as normas analíticas do Instituto Adolfo Lutz (2008): foram pesados aproximadamente 0,5 g de amostra em cartuchos de Sohxlet, os quais foram levados à estufa S. E. Fanem MOD 310 a $105^{\circ} \mathrm{C}$ e lá permaneceram por uma hora. Após secagem da amostra, os 
cartuchos contendo as amostras foram novamente pesados. Os cartuchos foram transferidos para o aparelho de Sohxlet, que é acoplado a um balão de fundo chato de $250 \mathrm{ml}$. Adicionou-se o solvente extrator (N-hexano), e esse conjunto foi mantido sob aquecimento na chapa aquecedora Tecnal TE-188. Ao extrator de Soxhlet, foi adaptado um condensador de bolas para o resfriamento dos solventes. A extração foi realizada por seis horas. Após esse período, os cartuchos foram retirados do aparelho extrator e transferidos para a estufa a $105^{\circ} \mathrm{C}$ por uma hora. Após secagem, foram pesados mais uma vez. O cálculo do teor de óleo foi feito pela diferença de peso dos cartuchos contendo as amostras antes e depois da extração. Os resultados foram expressos em porcentagem ou g óleo/100 g de amostra.

\subsection{Determinação do teor de proteínas}

O teor de proteínas foi determinado de acordo com as normas analíticas do Instituto Adolfo Lutz (2008). A determinação do nitrogênio das amostras foi realizada pelo método de Kjeldahl, que compreende três etapas: digestão, destilação e titulação.

Foram pesados aproximadamente $0,1 \mathrm{~g}$ de cada amostra, anotando-se o peso. Em seguida, as amostras foram transferidas para os tubos de digestão previamente codificados e organizados em uma bandeja, sendo o primeiro tubo o branco, o segundo a amostra padrão, e, o restante as amostras.

A seguir, foram acrescentados nos tubos aproximadamente $0,3 \mathrm{~g}$ de catalisador $\left(\mathrm{CuSO}_{4} / \mathrm{K}_{2} \mathrm{SO}_{4}\right)$, seguindo-se a adição de 3,5 $\mathrm{ml} \mathrm{de} \mathrm{H}_{2} \mathrm{SO}_{4}$ (ácido sulfúrico concentrado) e $2,0 \mathrm{ml}$ de peróxido de hidrogênio $30 \%$. Os tubos foram colocados no bloco digestor Tecnal TE007D, com temperatura inicial de $50{ }^{\circ} \mathrm{C}$, a qual sofreu aumentos progressivos até atingir $350^{\circ} \mathrm{C}$. As amostras permaneceram até toda a matéria orgânica ser "queimada", ou seja, quando as amostras apresentaram uma coloração esverdeada. Depois de esfriar, as amostras foram homogeneizadas e, então, foram adicionados $10 \mathrm{ml}$ de água ultrapura do purificador Milli-Q.

A destilação e titulação foram realizadas em equipamento Foss Tecator Kjeltech 2400, com adição de $30 \mathrm{ml}$ de $\mathrm{NaOH} 40 \%$, seguida da destilação. A titulação foi realizada utilizando-se ácido clorídrico $0,2 \mathrm{M}$, tendo como indicador o ácido bórico 1\% (mudança de coloração de verde para rosado).

O teor de proteína bruta foi calculado com base no volume gasto para a titulação, de acordo com a Equação (9.1) e utilizando o fator de conversão $\mathrm{F}=$ 6,25 para transformação do nitrogênio titulado em proteína. Os resultados foram expressos em porcentagem ou g proteína/100 g de amostra.

Cálculos: \% de proteína $=\frac{\mathrm{V} \times \mathrm{N} \times 14 \times 100 \times \mathrm{F}}{\mathrm{g} \mathrm{da} \text { amostra } \times 1000} \quad$ Equação (9.1) 
Onde:

$\mathrm{V}=$ volume de $\mathrm{HCl}$ gasto na titulação

$\mathrm{N}$ = normalidade do HCL

$\mathrm{F}=$ fator de conversão $(6,25)$.

\subsection{Determinação do teor de cinzas}

As cinzas ou resíduo mineral fixo foram determinados de acordo com as normas analíticas do Instituto Adolfo Lutz (2008). Os cadinhos de porcelana foram secos na estufa a $105^{\circ} \mathrm{C}$ por 2 horas, retirados com uma pinça e resfriados por aproximadamente 35 minutos. Os cadinhos foram pesados vazios e, também, após a adição de aproximadamente $0,5 \mathrm{~g}$ de amostra, os pesos foram registrados.

Os cadinhos foram transferidos para a mufla EDG 5000 P, com temperatura inicial de $150{ }^{\circ} \mathrm{C}$. A temperatura foi aumentada progressivamente até atingir $550{ }^{\circ} \mathrm{C}$. A incineração levou 5 horas aproximadamente, e a amostra ficou totalmente isenta de carvão, apresentando coloração branca ou acinzentada. A amostra foi retirada da mufla, resfriada e pesada. O resultado foi expresso em porcentagem ou g de cinzas/100 g amostra.

\subsection{Determinação do teor de carboidratos}

Após a determinação de umidade, proteínas, lipídios e cinzas, o teor de carboidratos do extrato de soja foi determinado por diferença: [100 - (umidade + proteínas + lipídios + cinzas)]. Para os grãos e extrato de soja liofilizado, foi determinado por diferença em base seca: [100 - (proteínas + lipídios + cinzas)].

\subsection{Tratamento dos dados}

Os dados obtidos na determinação da composição proximal, análise do processamento e análise sensorial foram submetidos à análise de variância (Anova) e teste de comparação de médias de Tukey $(\mathrm{p} \leq 0,05)$ utilizando o programa Assistat 7.7 versão beta (ASSIS, 2013).

\section{RESULTADOS E DISCUSSÃO}

O teste sensorial foi realizado em dois dias consecutivos, por 72 provadores não treinados, dos quais $54 \%$ eram do sexo masculino e $46 \%$, do feminino. A faixa etária prevalecente foi entre 20 e 30 anos (43\%).

Desses provadores, $74 \%$ informaram consumir produtos à base de soja. A proteína texturizada é o produto menos conhecido, pois $21 \%$ disseram que nunca 
a provaram. Os produtos mais preferidos foram as bebidas com sucos de frutas $(77 \%)$ e a soja cozida ( $74 \%$ ), enquanto o extrato apresentado puro (sem adição de frutas) e o tofu foram os produtos menos preferidos, com $13 \%$ e $14 \%$, respectivamente. Os resultados estão expressos no Gráfico 9.1.

\section{Apreciação dos produtos à base de soja}

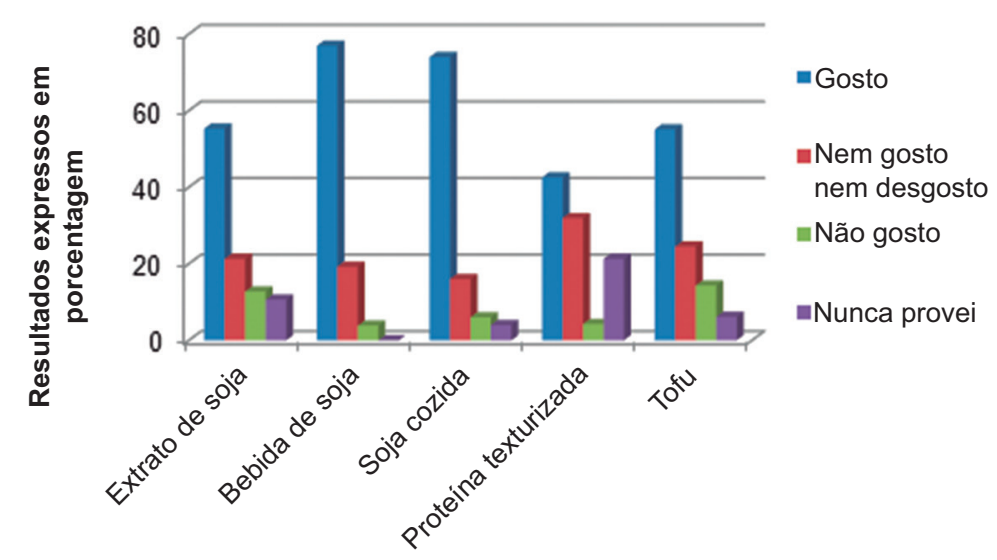

Gráfico 9.1 Apreciação dos produtos à base de soja

Os resultados obtidos na análise sensorial foram submetidos à análise de variância (Tabela 9.1). Embora as médias tenham variado desde 5,92 até 6,46, as amostras não apresentaram diferença significativa entre si.

Tabela 9.1 Média dos tratamentos do teste sensorial

\begin{tabular}{cc}
\hline Genótipos & Médias \\
\hline BRS 360 RR & $6,46^{a}$ \\
BRS 284 & $6,43^{a}$ \\
BRS 378 RR & $6,36^{a}$ \\
BRS 359 RR & $6,33^{a}$ \\
BRS 317 & $6,29 a$ \\
BRS 361 & $6,26^{a}$ \\
BR 09- 55277 RR1 & $6,10^{a}$ \\
BRS 232 & $5,92^{a}$ \\
\hline
\end{tabular}


Para considerar a aceitação de um produto em relação às suas propriedades sensoriais, é necessário um IA (índice de aceitabilidade) de no mínimo 70\% (Tabela 9.2), que pode ser obtido utilizando o cálculo IA $(\%)=\mathrm{A} \times 100 / \mathrm{B}$, onde $\mathrm{A}=$ nota média obtida para o produto e $\mathrm{B}=$ nota máxima dada ao produto (TEIXEIRA; MEINERT; BARBETTA, 1987).

Tabela 9.2 Índice de aceitabilidade dos genótipos testados sensorialmente por escala hedônica estruturada de 9 pontos

\begin{tabular}{cc}
\hline Genótipos & Índice de aceitabilidade (IA) \\
\hline BRS 360 RR & $71,78 \%$ \\
BRS 284 & $71,44 \%$ \\
BRS 378 RR & $70,67 \%$ \\
BRS 359 RR & $70,33 \%$ \\
BRS 317 & $69,89 \%$ \\
BRS 361 & $69,56 \%$ \\
BR 09- 55277 RR1 & $67,78 \%$ \\
BRS 232 & $65,78 \%$ \\
\hline
\end{tabular}

O índice de aceitabilidade mostra uma boa aceitação das amostras, principalmente para as cultivares transgênicas BRS 360 RR, BRS 378 RR, BRS 359 RR e para a cultivar convencional BRS 284, que apresentam um IA acima de $70 \%$. Porém, os resultados não foram satisfatórios para as cultivares convencionais BRS 232, BRS 317, BRS 361 e para a linhagem BR 09-55277 RR1, as quais obtiveram valores abaixo de $70 \%$.

Os resultados da escala hedônica podem ser também avaliados pela distribuição de frequências dos valores obtidos por cada amostra, usando histogramas, de forma a ressaltar visualmente seus níveis de aceitação e rejeição. O Gráfico 9.2 evidencia que a cultivar BRS 360 RR obteve maior média, não só em função da sua aceitação (maior porcentagem de notas entre 6 e 9) como da sua rejeição (a segunda menor porcentagem de notas entre 1 e 4); o contrário foi observado para a cultivar BRS 232, justificando a menor média obtida. É interessante notar que a cultivar BRS 361 destacou-se por apresentar maior frequência $(18,1 \%)$ de notas 5 , significando que um maior número de provadores não gostou nem desgostou desta cultivar (indiferença). 


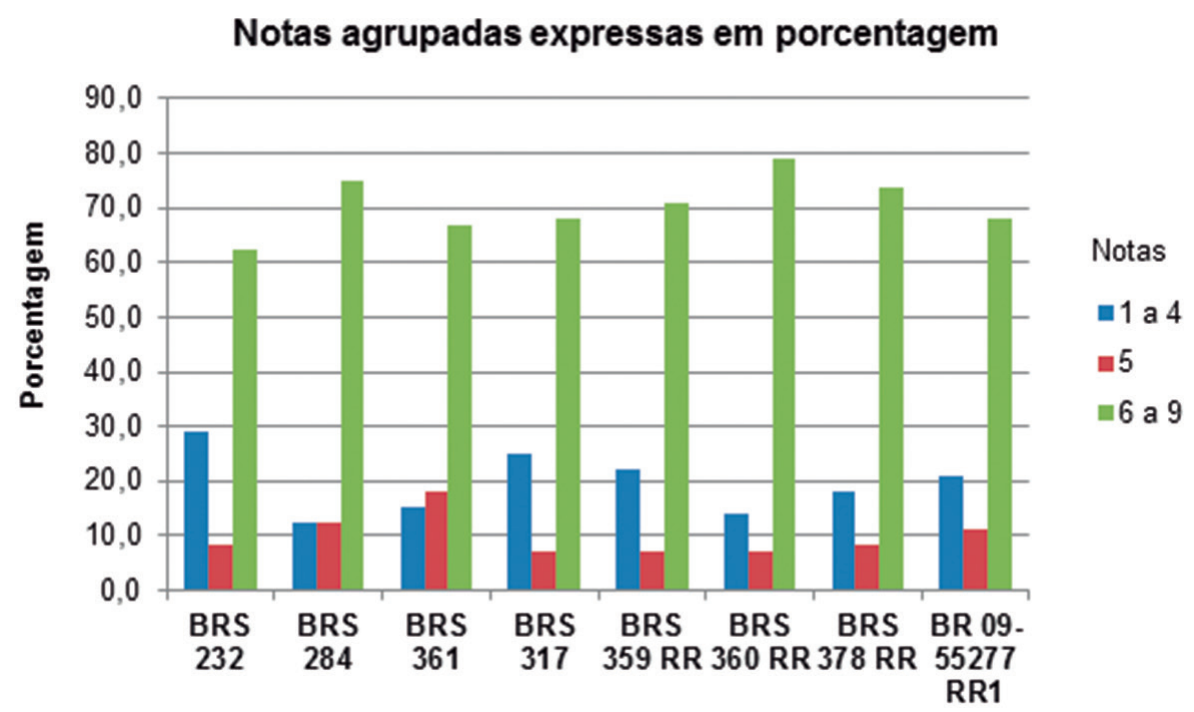

Gráfico 9.2 Notas agrupadas expressas em porcentagem

Como as cultivares BRS 284 e BRS 360 RR têm em comum o fato de apresentarem as maiores frequências de respostas positivas (6 a 9) e as menores de respostas negativas ( 1 a 4 ), considerou-se apropriado submetê-las a um novo teste sensorial de preferência.

O teste sensorial de preferência foi realizado por provadores não treinados, os quais receberam as duas amostras segundo um delineamento completo, totalmente aleatorizado e balanceado. A análise sensorial foi realizada em cabines individuais, e as amostras, codificadas com números de três dígitos, foram oferecidas simultaneamente, junto com uma ficha de avaliação.

Do total de 58 provadores, 26 preferiram a cultivar BRS $284(45 \%)$ e 32 preferiram a BRS 360 RR (55\%). Para que a diferença entre as amostras fosse significativa a nível de $5 \%$ de probabilidade, o número mínimo de respostas necessárias para estabelecer a preferência seria de 38 (MINIM, 2006), portanto não houve uma amostra preferida. Assim sendo, qualquer uma das cultivares testadas poderia ser utilizada comercialmente para produção de extrato de soja, com igual aceitação por parte dos consumidores.

BRS 232 foi a cultivar que apresentou a menor absorção de água, diferindo das cultivares convencionais BRS 284, BRS 361, das transgênicas BRS 359 RR, BRS 360 RR e da linhagem BR 09-55277 RR1. Apesar disso, as cultivares não apresentaram diferença significativa de rendimento entre si (Tabela 9.3). 
Aceitabilidade de extrato de soja elaborado com grãos de genótipos brasileiros...

Tabela 9.3 Rendimento em extrato e água absorvida na maceração dos grãos dos genótipos de soja

\begin{tabular}{ccc}
\hline Genótipos & Água absorvida $(\mathrm{g})$ & Rendimento em extrato $(\mathrm{g} / 100 \mathrm{~g})$ \\
\hline BRS 232 & $195,12 \pm 2,32^{\mathrm{b}}$ & $1028,95 \pm 15,41^{a}$ \\
BRS 284 & $211,80 \pm 4,46^{a}$ & $1059,10 \pm 20,93^{a}$ \\
BRS 317 & $206,05 \pm 9,95^{a b}$ & $1060,56 \pm 11,36^{a}$ \\
BRS 361 & $218,80 \pm 10,77^{a}$ & $1035,29 \pm 7,41^{a}$ \\
BRS 359 RR & $221,05 \pm 4,79^{a}$ & $1041,88 \pm 20,03^{a}$ \\
BRS 360 RR & $218,55 \pm 3,93^{a}$ & $1056,00 \pm 23,79^{a}$ \\
BRS 378 RR & $208,08 \pm 3,98^{a b}$ & $1026,73 \pm 24,76^{a}$ \\
BR 09-55277 RR 1 & $217,20 \pm 9,92^{a}$ & $1060,40 \pm 10,62^{a}$ \\
\hline
\end{tabular}

Letras diferentes na mesma coluna indicam diferença significativa (Tukey, $p \leq 0,05)$. Média de 4 determinações \pm desvio padrão.

Os valores encontrados para a composição proximal dos grãos dos genótipos de soja estudados estão sumariados na Tabela 9.4. Quanto ao teor de umidade, não houve diferença significativa entre os genótipos estudados. Com relação ao teor de proteínas, a cultivar geneticamente modificada BRS 359 RR foi aquela que apresentou maior valor, 37,82 g/100,g, e a linhagem BR 09-55277 RR1 foi a que apresentou o menor valor, $32,39 \mathrm{~g} / 100 \mathrm{~g}$.

Tabela 9.4 Composição proximal dos grãos dos oito genótipos de soja estudados

\begin{tabular}{|c|c|c|c|c|c|}
\hline Genótipos & Umidade $^{1}$ & Proteína ${ }^{2}$ & Lipideos $^{2}$ & Cinzas $^{2}$ & Carboidratos $^{2,3}$ \\
\hline BRS 232 & $6,86 \pm 0,25^{a}$ & $35,17 \pm 0,35^{c}$ & $22,57 \pm 0,11^{d}$ & $6,12 \pm 0,16^{b c}$ & $36,15 \pm 0,37^{a b}$ \\
\hline BRS 284 & $6,89 \pm 0,11^{a}$ & $35,35 \pm 0,21^{b c}$ & $24,87 \pm 0,85^{\mathrm{ab}}$ & $8,51 \pm 0,01^{a}$ & $31,27 \pm 0,52^{d}$ \\
\hline BRS 317 & $7,26 \pm 0,13^{a}$ & $35,50 \pm 0,47^{b c}$ & $23,19 \pm 0,25^{\mathrm{bcd}}$ & $5,85 \pm 0,15^{\mathrm{cd}}$ & $35,47 \pm 0,54^{a b c}$ \\
\hline BRS 361 & $6,94 \pm 0,27^{a}$ & $33,26 \pm 0,35^{d}$ & $24,39 \pm 0,16^{a b c}$ & $5,82 \pm 0,03^{d}$ & $36,53 \pm 0,45^{a}$ \\
\hline BRS 359 RR & $7,32 \pm 0,09 a$ & $37,82 \pm 0,21^{a}$ & $22,84 \pm 0,48^{\mathrm{cd}}$ & $8,62 \pm 0,16^{a}$ & $30,73 \pm 0,26^{d}$ \\
\hline BRS 360 RR & $7,07 \pm 0,37^{a}$ & $36,07 \pm 0,29 b$ & $23,17 \pm 0,50^{\mathrm{bcd}}$ & $5,97 \pm 0,00^{c d}$ & $34,80 \pm 0,38^{c}$ \\
\hline BRS 378 RR & $7,16 \pm 0,31^{a}$ & $34,89 \pm 0,2^{c}$ & $24,05 \pm 0,33 \mathrm{abcd}$ & $5,83 \pm 0,05^{d}$ & $35,23 \pm 0,40^{b c}$ \\
\hline $\begin{array}{c}\text { BR 09- } \\
55277 \text { RR } 1\end{array}$ & $7,38 \pm 0,11^{a}$ & $32,39 \pm 0,25^{\mathrm{e}}$ & $25,72 \pm 0,47^{a}$ & $6,37 \pm 0,22^{b}$ & $35,52 \pm 0,54^{a b c}$ \\
\hline
\end{tabular}
ções \pm desvio padrão. (1) resultados expressos em g/100 g matéria integral; (2) resultados expressos em $\mathrm{g} / 100 \mathrm{~g}$ matéria seca; (3) resultados calculados por diferença, média de 3 repetições. 
O teor de lipídeos apresentou uma diferença entre o menor e o maior valor encontrado de apenas $3,15 \mathrm{~g} / 100 \mathrm{~g}$, apresentando diferença significativa $(\mathrm{p} \leq 0,05)$. O teor de cinzas variou de 5,82 g/100 g para a cultivar BRS 361 a 8,62 g/100 g para a cultivar BRS 359 RR. Para o teor de carboidratos, o maior valor encontrado foi para a cultivar BRS $361(36,53 \mathrm{~g} / 100 \mathrm{~g})$, porém, sem diferir significativamente das cultivares BRS 232 (36,15 g/100 g), BRS 317 (35,47 g/100 g), e da linhagem BR 09-55277 RR1 (35,53 g/100 g). Os menores valores foram de 30,73 g/100 g e 31,27 g/100 g, para as cultivares BRS 359 RR e BRS 284, respectivamente.

Os resultados obtidos para a composição proximal dos extratos de soja liofilizados estão sumarizados na Tabela 9.5. Não houve diferença significativa quanto ao teor de umidade dos extratos liofilizados dos genótipos de soja estudados. Com relação ao teor de proteínas, a cultivar geneticamente modificada BRS 359 RR foi aquela cujo extrato liofilizado apresentou o maior teor, $45,86 \mathrm{~g} / 100 \mathrm{~g}$, e o menor valor encontrado foi para o extrato liofilizado da linhagem BR 09-55277 RR1, com um valor igual a 37,73 g/100 g. O teor de lipídeos apresentou uma variação entre $22,40 \mathrm{~g} / 100 \mathrm{~g}$, para a cultivar BRS 232, a 28,40 g/100 g, para a cultivar BRS 361. O teor de cinzas variou entre $5,62 \mathrm{~g} / 100 \mathrm{~g}$, para a cultivar BRS 361, a 11,13 g/100 g, para a cultivar BRS 359 RR. Com relação aos carboidratos, o maior valor encontrado foi para a cultivar BRS 317 (27,27 g/100 g), diferindo estatisticamente de BRS 359 RR (20,22 g/100 g), BRS 360 RR (23,72 g/100 g) e BRS 378 RR (20,75g/100 g).

Tabela 9.5 Composição proximal dos extratos liofilizados obtidos a partir dos genótipos de soja estudados

\begin{tabular}{|c|c|c|c|c|c|}
\hline Genóti & & & & & \\
\hline BRS 232 & & 42,41 & & $8,48 \pm 0,13^{c}$ & \\
\hline & & & & $7,94 \pm 0$ & \\
\hline & & 41,5 & & $5,86 \pm 0,02^{d}$ & \\
\hline BRS 361 & $5,83 \pm 0,01^{a}$ & $39,80 \pm 0,49^{f}$ & $28,40 \pm 0,59 a$ & $5,62 \pm 0,05^{d}$ & $26,17 \pm 0,40^{a b}$ \\
\hline RS 359 RR & $6,20 \pm$ & $45,86=$ & $22,79 \pm 0,83^{c}$ & $3 \pm 0,41^{\mathrm{a}}$ & $2 \pm 0,41^{c}$ \\
\hline 3RS 360 RR & $6,19 \pm 0,21^{a}$ & $44,46 \pm 0,21^{b}$ & $22,45 \pm 0,71^{c}$ & $9,38 \pm 0,33^{b}$ & $23,72 \pm 0,42^{b}$ \\
\hline BRS 378 RR & $6,14 \pm 0,07^{a}$ & $43,13 \pm 0,37 c$ & $25,48 \pm 0,03^{b}$ & $10,64 \pm 0,10^{a}$ & $20,75 \pm 0,31^{c}$ \\
\hline $\begin{array}{l}\text { BR 09- } \\
5277 \text { RR } 1\end{array}$ & $5,75 \pm 0,10^{a}$ & $37,73 \pm 0,35^{9}$ & $25,65 \pm 0,28^{b}$ & $10,49 \pm 0,6$ & $26,32 \pm 0,68^{a b}$ \\
\hline
\end{tabular}

Letras diferentes na mesma coluna indicam diferença significativa (Tukey, $p \leq 0,05)$. Média de 3 determinações \pm desvio padrão. (1) resultados expressos em g/100 g matéria integral; (2) resultados expressos em $\mathrm{g} / 100 \mathrm{~g}$ matéria seca; (3) resultados calculados por diferença, média de 3 repetições. 
Os resultados encontrados para a composição proximal dos extratos de soja estão sumariados na Tabela 9.6. Houve diferença significativa quanto ao teor de umidade, e a cultivar geneticamente modificada BRS 359 RR foi aquela cujo extrato apresentou o maior teor, porém, sem diferir estatisticamente do extrato da cultivar BRS 378 RR. Com relação ao teor de proteínas, o extrato obtido a partir da cultivar BRS 232 foi aquele que apresentou o maior teor (1,29 g/100 g), e o menor valor encontrado foi de $0,99 \mathrm{~g} / 100 \mathrm{~g}$ para a linhagem BR 09-55277 RR1. Os maiores valores encontrados para o teor de lipídeos nos extratos foram $0,79 \mathrm{~g} / 100 \mathrm{~g}$, para a cultivar BRS 284, e $0,78 \mathrm{~g} / 100 \mathrm{~g}$, para a cultivar BRS 361; os menores valores foram $0,58 \mathrm{~g} / 100 \mathrm{~g}$ e $0,60 \mathrm{~g} / 100 \mathrm{~g}$, para as cultivares geneticamente modificadas BRS 359 RR e BRS 360 RR, respectivamente. Para o teor de cinzas, os maiores valores encontrados nos extratos foram $0,28 \mathrm{~g} / 100 \mathrm{~g}$, para as cultivares geneticamente modificadas BRS $359 \mathrm{RR}$ e BRS $378 \mathrm{RR}$, e 0,27 g/100 g, para a linhagem BR 09-55277 RR1; e os menores valores foram de 0,16 g/100 g, para as cultivares BRS 317 e BRS 361. Com relação ao teor de carboidratos, a cultivar BRS 232 foi aquela que apresentou o maior valor, 0,81 g/100 g, porém, sem diferir estatisticamente da cultivar BRS 284 (0,79 g/100 g); e as cultivares geneticamente modificadas BRS 359 RR e BRS $378 \mathrm{RR}$ foram as que apresentaram os menores valores, $0,51 \mathrm{~g} / 100 \mathrm{~g}$ e $0,54 \mathrm{~g} / 100 \mathrm{~g}$, respectivamente.

Tabela 9.6 Composição proximal dos extratos de soja obtidos a partir dos grãos de oito genótipos de soja diferentes (resultados expressos em $\mathrm{g} / 100 \mathrm{~g}$ matéria integral)

\begin{tabular}{|c|c|c|c|c|c|}
\hline Genótipos & Umidade & Proteína & Lipídeos & Cinzas & Carboidratos ${ }^{1}$ \\
\hline BRS 232 & $96,96 \pm 0,04^{d}$ & $1,29 \pm 0,00^{a}$ & $0,68 \pm 0,02^{b}$ & $0,26 \pm 0,00^{\text {bc }}$ & $0,81 \pm 0,01^{a}$ \\
\hline BRS 284 & $97,04 \pm 0,05^{d}$ & $1,21 \pm 0,01^{b}$ & $0,79 \pm 0,01^{a}$ & $0,24 \pm 0,01^{d}$ & $0,79 \pm 0,07^{a b}$ \\
\hline BRS 317 & $97,33 \pm 0,01^{b c}$ & $1,11 \pm 0,01^{\mathrm{e}}$ & $0,68 \pm 0,00^{b}$ & $0,16 \pm 0,00$ & $0,73 \pm 0,01^{b c}$ \\
\hline BRS 361 & $97,24 \pm 0,05^{c}$ & $1,10 \pm 0,01^{\mathrm{e}}$ & $0,78 \pm 0,02^{a}$ & $0,16 \pm 0,00^{e}$ & $0,72 \pm 0,01^{b c}$ \\
\hline BRS 359 RR & $97,49 \pm 0,03^{a}$ & $1,15 \pm 0,01^{d}$ & $0,58 \pm 0,02^{c}$ & $0,28 \pm 0,01^{a}$ & $0,51 \pm 0,01^{\mathrm{e}}$ \\
\hline BRS 360 RR & $97,33 \pm 0,00^{b c}$ & $1,17 \pm 0,01^{c}$ & $0,60 \pm 0,02^{c}$ & $0,25 \pm 0,01^{c d}$ & $0,63 \pm 0,01^{d}$ \\
\hline BRS 378 RR & $97,42 \pm 0,02^{a b}$ & $1,12 \pm 0,01^{\mathrm{e}}$ & $0,66 \pm 0,00^{b}$ & $0,28 \pm 0,00^{a b}$ & $0,54 \pm 0,01^{\mathrm{e}}$ \\
\hline $\begin{array}{c}\text { BR 09-55277 } \\
\text { RR } 1\end{array}$ & $97,39 \pm 0,05^{b}$ & $0,99 \pm 0,01^{f}$ & $0,68 \pm 0,00^{b}$ & $0,27 \pm 0,02^{\mathrm{ab}}$ & $0,69 \pm 0,02^{\text {cd }}$ \\
\hline
\end{tabular}

Letras diferentes na mesma coluna indicam diferença significativa (Tukey, $p \leq 0,05)$. Média de 3 determinações \pm desvio padrão. (1) resultados calculados por diferença, média de 3 repetições. 


\section{CONCLUSÃO}

Os genótipos estudados (cultivares convencionais, cultivares geneticamente modificadas e uma linhagem) apresentaram algumas diferenças com relação à sua composição proximal. A cultivar geneticamente modificada BRS 359 RR foi aquela que se destacou em relação ao teor de proteínas nos seus grãos, umidade no extrato e teor de cinzas tanto nos grãos quanto no extrato, porém, foram observados teores baixos de carboidratos, tanto nos grãos quanto no extrato de soja. O menor teor de proteínas encontrado, tanto nos grãos quanto no extrato, foi para a linhagem BR 09-55277 RR1, porém, foi observado um alto valor de lipídeos nos seus grãos, o que já era de se esperar, pois há uma relação inversamente proporcional entre teor de proteínas e lipídeos nos grãos de soja de um mesmo genótipo.

Apesar da diferença significativa na absorção de água durante o processo de obtenção dos extratos, não houve diferença significativa em relação ao rendimento entre os genótipos estudados.

As cultivares transgênicas BRS 360 RR, BRS 378 RR, BRS 359 RR e a cultivar convencional BRS 284 apresentaram os maiores índices de aceitabilidade. No entanto, não houve diferença significativa na aceitação sensorial dos extratos de soja obtidos dos oito genótipos de soja utilizados neste trabalho. Por conseguinte, todos estão aptos para servirem de matéria-prima para a produção de extratos de soja.

\section{REFERÊNCIAS}

ASSIS, F. Assistat 7.7 versão Beta. Disponível em: <http://www.assistat.com/indexp. html>. Acesso em: 4 out. 2013.

BENASSI, V. T.; MANDARINO, J. M.G.; CARRÃO-PANIZZI, M. C. O Sabor da Soja: O segredo para preparar pratos saborosos com soja. Folder 07/2012.

BORDINGNON, J. R.; MANDARINO, J. M. G. Soja: composição química, valor nutricional e sabor. Londrina: Embrapa, 1994.

BRASIL. Ministério da Agricultura, Pecuária e Abastecimento. Cultura: Soja. Disponível em: http:<http://www.agricultura.gov.br/vegetal/culturas/soja> Acesso em: 25 jun. 2013. CARRÃO-PANIZZI, M. C. Valor nutritivo da soja e potencial de utilização na dieta brasileira. Londrina: Embrapa, 1988.

CARRÃO-PANIZZI, M. C.; MANDARINO, J. M. G. Soja: Potencial de Uso na Dieta Brasileira. Londrina: Embrapa, 1998.

COMPANHIA NACIONAL DE ABASTECIMENTO. Acompanhamento de safra brasileira: grãos, décimo levantamento, julho 2013. Brasília: Companhia Nacional de Abastecimento - Conab, 2013.

DADOS de Mercado, 2011. Disponível em: <http://abir.org.br/2011/10/24/dados-demercado-2011/>. Acesso em: 23 out. 2013. 
DALL'AGNOL, A. et al. O complexo agroindustrial da soja brasileira. Circular Técnica 43. Londrina: Embrapa, 2007.

DUTCOSKY, S. D. Análise sensorial de alimentos. 2. ed. Curitiba: Champagnat, 2007. EMPRESA BRASILEIRA DE PESQUISA AGROPECUÁRIA. Soja na alimentação:

Técnicas de preparo. Disponível em: <http://www.cnpso.embrapa.br/soja_alimentacao/ index.php?pagina =3> Acesso em: 30 jul. 2013.

. Soja: História. Disponível em: <http://www.cnpso.embrapa.br/index.php?op_ page $=112 \&$ cod_pai=33>. Acesso em: 24 jun. 2013.

FELBERG, I. et al. Obtenção artesanal de extrato de soja sob diferentes condições de preparo. Comunicado técnico 82. Londrina: Embrapa, 2005.

INSTITUTO ADOLFO LUTZ (São Paulo). Procedimentos e determinações gerais. Métodos físico-químicos para análise de alimentos. 1. ed. Digital. São Paulo: Instituto Adolfo Lutz, 2008. P. 83-158.

MENDONÇA, D. Mercado Saudável. Giro News, n. 160, p. 30-31, mar. 2010. Disponível em: <http://www.gironews.com/revistas/revista-161-854.pdf>. Acesso em: 23 out. 2013.

MINIM, V. P. R. Análise sensorial: estudos com consumidores. Viçosa: UFV, 2006.

ROSSI, E. A; ROSSI, P. R. Bebidas funcionais à base de soja. In: VENTURINI FILHO, W. G. Bebidas não alcoólicas: ciência e tecnologia. 1. ed. São Paulo: Blucher, 2010. p. 57-79. SOARES, N. Leite da terra. Engarrafador Moderno, São Caetano do Sul, n. 208, p. 1218, set. 2011.

STONE, H.; SIDEL, J. L. Sensory Evaluation Practices. 3. ed. Food Science and Technology, International Series. Elsevier Academic Press, 2004. 365 p.

TEIXEIRA, E.; MEINERT, E. M, BARBETTA, P. A. Análise Sensorial de Alimentos. Florianópolis: UFSC, 1987.

ZADINELLO, R. E. et al. Métodos de extração, formulação e avaliação sensorial de produto à base de extrato hidrossolúvel de soja. Varia Scientia Agrárias, v. 1, n. 1, p. 111-120, jan. 2010. 
